\title{
Effect of the Reduction in the Frequency of Injections of Pituitary Extracts During a Superovulation on the Embryo Collection Results in Cows in Algeria
}

\author{
Djallal ADEL ${ }^{1 *}$, Kamal TOUATI ${ }^{2}$, Rachid KAIDI ${ }^{1}$ \\ ${ }^{1}$ Laboratory of Animal Reproduction Biotechnology, Institute of Veterinary Sciences, University of BLIDA \\ -1-, PB 270 Route of Soumaa, Blida, Algeria. \\ ${ }^{2}$ Ruminants and pigs, Faculty of Veterinary Medicine, University of Liège, Belgium \\ * Corresponding author: adel_djalle@yahoo.fr \\ Bulletin UASVM Veterinary Medicine 75(1)/2018 \\ Print ISSN 1843-5270; Electronic ISSN 1843-5378 \\ doi:10.15835/buasvmcn-vm:001217
}

\begin{abstract}
The aim of this study is to verify the efficacy of a superovulation treatment with 3 injections of pituitary extracts (Stimufol@) 24 hours apart and compare the results to a standard protocol (8 injections 12 hours apart), with a total dose of $500 \mu \mathrm{g}$. Twenty-three embryos collections were conducted after two superovulation protocols, the first with 8 injections 12 hours apart and decreasing doses ( $n=11$, group 1 ) and the second 3 injections at constant doses 24 hours of interval ( $\mathrm{n}=12$, group 2). The average number of lutea corpora obtained is 9.1 per cow for group 1 and 10.4 in group 2. A total number of 140 embryos were collected with an average of 6.08 per cow. Among the embryos collected, 46 and 56 per cent were transferable respectively in group 1 and 2. A little quality gain was recorded in group 2 with an average transferable embryo of 3.8 against 2.2 for group1. In our study we observed the same efficacy for both treatments with a little quality improvement (almost one transferable embryo) when reducing the number of injections at the time of superovulation treatment, the same gain minimal in elite cows can have a significant economic impact.
\end{abstract}

Keywords: cattle, embryo production, pituitary extracts, superovulation.

\section{Introduction}

Improving fertility is a major concern and a priority for the cattle breeder aiming at optimizing the production potential of his animals. Much effort has been focused on genetic improvement and the selection of more productive animals (Schutz and Pajor, 2001). This benefit brought by the selection had a negative impact by decreasing fertility. Barbat et al. (2005) report that in Prim 'Holstein, 30 to $50 \%$ of the drop in success rate at first insemination is due to the genetic improvement built around the increase in milk production. In Algeria the success rate at first insemination varies from $50 \%$ (Ghozlane et al., 2006) to $18.16 \%$ (Ghozlane et al., 2010).
Embryo transfer represents a very good alternative to take advantage of both ascendants genetic potential. The selection occurring at father side as well as at mother side, the use of local breed rustic and disease-resistant recipients and the birth of calves with high genetic potential adapted to the country conditions will result in rapid multiplication of cattle with interesting production potential.

Acquired knowledge in the field of ovarian physiology and follicular growth mechanisms alongside with sonography development (Grizelj et al., 2013), have helped develop the hormonal treatments in order to limit the waste of follicles by atresia. It is to know that $99 \%$ of follicular reserve is lost half way, even before maturation (Drion 
et al., 1996; Hanzen et al., 2000; Monniaux et al., 1983) which does not help multiply the genetic potential of elite females.

In Algeria few works have been carried out in the field of bovine embryos production in cattle. An average of 4 embryos per cow has been recorded in 2003 in a trial at station (Adel, 2003). In autochthonous bovine populations the first results have been achieved in 2004 with an average of 5 embryos per cow of which 2.33 were transferable (Ferrouk et al., 2008).

However, the large variability of embryos production results is a limiting factor for several reasons. Indeed a cow subjected to a treatment may give from 0 to 50 embryos. Nibart (1991) reports that 10 to $20 \%$ of the cows do not give any response to superovulation treatment and $24 \%$ of collections provide no viable embryo (Mapletoft et al., 2013). This variability is due to intrinsic factors related to the animal (genetic, pregnancy rate...) and extrinsic ones related to the environment like alimentation (Butler, 2000). Among these factors we find the method of superovulation treatment (Kanitz et al., 2002). The multiplicity of injections during a superovulation treatment using FSH (8 injections 12 hours apart) could produce a stressful effect, harmful to the embryos development (Rutledge, 2001). This stress could be decreased by reducing the number of injections. Some studies have investigated the effect of superovulation hormones injections frequency on embryo collection results. Tribulo et al. (2012) have performed only a single injection of diluted FSH with hyaluronic acid, but no significant difference was observed compared to the classic protocol with 8 injections.

The aim of the study was to compare cows' response to two superovulation protocols. The first, is the classic one, consists of 8 injections 12 hours apart, the second consists of three injections 24 hours apart using the same solution at constant and higher doses than the classic protocol.

\section{Materials and methods}

\section{Animals}

The research has been carried out between October 2010 and November 2011 on a dairy farm in the region of Chiffa, $40 \mathrm{~km}$ southern Algiers, the capital of Algeria. It is situated in the plain of Mitidja beneath latitude of $36.46^{\circ} \mathrm{N}$ and a longitude of $2.81^{\circ} \mathrm{E}$. The farm owns 120 dairy cows, 30 calves and ten bulls intended for fattening. Ten multiparous cows divided into two groups were included in the study, they are 4 to 6 years old and they have a BCS (Body Condition Score) of 3.5 to 4 estimated through external appearance criteria according to Shröder and Staufenbiel assessment table (Schröder and Staufenbiel, 2006). They show a regular cycle by visual observation of three successive estrus cycles, and do not present any gynecologic pathology at clinical examination. All animals are kept under the same breeding conditions and receive the same alimentation composed mainly of oat hay and concentrate throughout the year. This ration is supplemented by a supply of green fodder with hybrid sorghum during the summer (from June to August and sometimes until September), and forage clover between February and April.

\section{Media and drugs}

A commercial solution of pituitary extracts (Stimufol $®$ ) was used for superovulation treatment. A phosphate buffer-based collection medium (Euroflush IMV technologies, l'aigle France) and a holding medium (IMV technologies, l'aigle France) consisting of PBS solution supplemented with $4 \mathrm{~g} / \mathrm{l}$ of BSA (Bovine Serum Albumin), antibiotics and antifungals were used for embryo collections.

\section{Collection equipment}

Collection equipment consists of two-ways catheter (Woerlein CH 18) provided with a metal mandrel. For embryos detection, identification and packaging we used an inverted microscope at the lowest magnification, round Petri dishes of 60 $\mathrm{mm}$ of $\varnothing$ (squared) and $35 \mathrm{~mm}$ of $\emptyset$, and the 0.25 $\mathrm{ml}$ straws for embryos packaging. Sanitary jackets have served to protect the collection catheter.

\section{Superovulation treatments and embryos collection}

The superovulation treatments were performed over the whole year. A total dose of $500 \mu \mathrm{g}$ of Stimufol $\AA$ was injected following a specific protocol. An injection of $5 \mathrm{mg}$ of etiproston (Prostavet, VIRBAC) was performed on the $3^{\text {rd }}$ day of treatment. Inseminations were performed at 48 and 60 hours after prostaglandin injection. Protocols in both groups are implemented between the $9^{\text {th }}$ and the $11^{\text {th }}$ day of the estrous cycle as follows:

Group 1: the cows receive classic superovulation treatment with 8 injections of a $500 \mu \mathrm{g}$ 
pFSH solution diluted into $10 \mathrm{ml}$ of solvent up to 2 injections per day 12 hours apart at decreasing doses $(100 \mu \mathrm{g} / 100 \mu \mathrm{g}, 75 \mu \mathrm{g} / 75 \mu \mathrm{g}, 50 \mu \mathrm{g} / 50 \mu \mathrm{g}$, $25 \mu \mathrm{g} / 25 \mu \mathrm{g})$.

Group 2: the cows receive a superovulation treatment consisting of 3 injections of $500 \mu \mathrm{g} \mathrm{pFSH}$ solution diluted into $9 \mathrm{ml}$ of solvent to 24 hours apart and at constant doses of $166.6 \mu \mathrm{g}$.

Collections were performed on the $7^{\text {th }}$ day after artificial insemination by cervical route. Each cow was collected at least twice during the study period. The embryos were classified according to the model proposed by Eldsen et al. (1978), and then packaged in transparent straws. We considered the embryos of $1^{\text {st }}, 2^{\text {nd }}$ and $3^{\text {rd }}$ classes as suitable, the degenerated ones were counted within the whole number of embryos and the unfertilized were put apart.

\section{Statistical analysis}

The data were processed thanks to system 7.0 software. The comparison of the ovarian response results and the embryos number and quality between the two protocols ( 3 vs. 8 injections) was performed with Kruscal-wallis test. Differences were considered significant for $\mathrm{p}<0.05$.

\section{Results}

During the 12 months of the study, 23 collections were made in total. The Tab. 1 shows the overall result of the embryos collections in terms of the superovulation protocol.

The ovarian response was low. This is due to the existence of several collections with a number of corpora lutea counts of less than 10 per cow in both groups.

The overall number of embryos in both groups is 140 (62 and 78 respectively for group 1 and 2) and the overall average is 6.08 per cow with a slight advantage for group $2(5.6 \pm 1.2$ and $6.5 \pm 1.5$ respectively for group 1 and 2). Despite the small average of embryos per cow in both groups, the proportions of suitable embryos remain correct particularly in group 2 with $56.41 \%$ against $45.16 \%$ for group 1.

Even if the difference was not statistically significant, the embryos quality was slightly better in group 2 than group 1 (Tab. 2). In fact, 71 transferable embryos were collected, with 46 versus 25 and averages of $3.83 \pm 0.99$ versus 2.27 \pm 0.94 for group 2 and 1 respectively. About the embryos of class 1, 25 versus 12 and averages

Table 1: Overall result of embryos collections in both groups.

\begin{tabular}{lcc}
\hline & \multicolumn{2}{c}{ groups } \\
\cline { 2 - 3 } Parameters & group1 & group 2 \\
\cline { 2 - 3 } Collections & 11 & 12 \\
CL $(\overline{\mathbf{x}} \pm$ SEM) & $9.09 \pm 2$ & $10.41 \pm 1.82$ \\
Embryos ( $\overline{\mathbf{x}} \pm$ SEM) & $5.63 \pm 1.22$ & $6.5 \pm 1.49$ \\
Transferable ( $\overline{\mathbf{x}} \pm$ SEM) & $2.27 \pm 0.94$ & $3.83 \pm 0.99$ \\
Transferable/collected (\%) & 45.16 & 56.41 \\
\hline
\end{tabular}

Collected embryos: Class 1, 2, 3 and 4 (degenerated); SEM: Standard Error of the Mean

Table 2: Comparison of the quality of the embryos of the two superovulation protocols

\begin{tabular}{|c|c|c|c|c|}
\hline Parameters & & & Group 1 & Group 2 \\
\hline \multirow{3}{*}{$\begin{array}{l}\text { Fertilized } \\
(\bar{x} \pm \text { SEM })\end{array}$} & \multirow{2}{*}{ Transferable } & $\mathrm{Cl} 1$ et 2 & $2 \pm 0.9$ & $2.83 \pm 0.8$ \\
\hline & & $\mathrm{Cl} 3$ & $0.27 \pm 0.12$ & $1 \pm 0.32$ \\
\hline & Non-transferable & $\mathrm{Cl} 4$ and degenerated & $1.81 \pm 0.68$ & $2.16 \pm 0.6$ \\
\hline $\begin{array}{l}\text { unfertilized } \\
(\bar{x} \pm S E M)\end{array}$ & & & $1.54 \pm 0.6$ & $0.83 \pm 0.37$ \\
\hline
\end{tabular}

SEM: Standard Error of the Mean 
of $2.33 \pm 0.77$ versus $1.09 \pm 0.71$ were recorded for group 2 and 1 respectively. Regarding the non-transferable embryos (degenerated and non-fertilized), no difference has been observed between group 1 and 2 with averages of $3.36 \pm$ 0.98 and $3 \pm 0.75$ respectively.

The design of the conventional superovulation protocol imposes the multiplicity of injections, because of the very short half-life of the pituitary extracts used (Demoustier et al., 1988). Thus twicedaily injections for four days (eight injections in total) are necessary, which is very stressful for animals.

We performed 23 collections in two groups of donors to see whether a possible advantage can be brought by reducing the number of injections during the superovulation treatment. In spite of prior gynecologic examination and cyclicity follow-up, the lack of livestock conditions control (especially alimentation) may have affected ovarian reactions and collection results in both groups. In fact the action of alimentation on the ovarian activity and the fertility has been well demonstrated (Butler, 2000).

In the present study, the ovarian response was low with an overall corpora lutea average of about 9.8 (9.09 and 10.4 for group 1 and 2 respectively) (Garcia Guerra et al., 2012; Bo et al., 1991). This could be explained by a poor cattle management, in particular, an energy excess in alimentation. Indeed, a rich intake of fast fermentable food can induce a sub-acute rumen acidosis which is harmful to reproduction (Barnouin and Chacornac, 1992). Furthermore, a fertility decrease of $53 \%$ can be caused by a concentrate daily intake between 400 and 500 gr (Poncet, 2002). An increase in the follicular cysts frequency has also been reported by Paragon (1991). This condition has been noticed in our herd and has led on several occasions to postpone superovulation treatments.

In our work the comparison of the ovarian reaction as well as the recoveries results between the two protocols ( 8 vs. 3 injections) showed no significant difference. The same finding was reported by Purwantara et al. (1994), Donaldson (1990) as for him has obtained the same mean number of transferable embryos with 5.5 and 5.3 respectively for the protocols with 8 and 3 injections. Other authors have investigated the effect of reducing the number of injections by comparing the results of multiple intramuscular injections protocol to the one with a single subcutaneous injection (Misra et al., 1992; Hockley et al., 1992; Bo et al., 1994; Kelly et al., 1997). These studies show the same efficiency for both protocols. In our work, we observed a slight gain in collected embryos quality in favor of group 2 (the protocol with 3 injections). This could be explained by the reduction of the stress effect imposed by superovulation treatment by reducing the number of injections.

Indeed stress deleterious action on fertility has been reported by several authors (Putney et al., 1988; Nibart, 1991; Dobson et al., 2001) which is most often materialized either by delayed development by the embryos degeneration. According to Nibart (1991), the occurrence of any stress before or during a superovulation treatment leads to an increase in the ACTH secretion and prevents the appearance of the LH peak. Thus it promotes the formation of cysts and poor quality ova.

\section{Conclusions}

A superovulation protocol based on 3 injections 24 hours apart of pituitary extracts (Stimufol ${ }^{\circledR}$ ) could replace the conventional protocol (8 injections 12 hours apart) in cows. This 3 injections protocol has the advantage to reduce the constraints on the animal and on the operator.

A slight improvement of embryos quality has been recorded in favor of the 3 injections protocol. An optimization of the experimentation conditions (increasing the livestock size and the number of embryos collections, a better control of the breeding conditions) could highlight this qualitative improvement.

These findings may have a direct impact on the cost of embryos production in cows. On one hand the reduction in injections number reduces considerably the cost of veterinarian's displacements during the superovulation. On the other hand the possible improvement of the embryos quality (following the reduction of the stress imposed by injections multiplicity) increases donors yield.

Acknowledgments. This research did not receive any specific grant from funding agencies in the public, commercial, or not-for-profit sectors. 


\section{References}

1. Adel D (2003). Comparative study of two pituitary extracts in the production of embryos in cattle. Theses. Agro-Veterinary Faculty, University of Blida, Algeria.

2. Barbat A, Druet T, Bonaiti B, Guillaume F, Colleau JJ (2005). Overview of phenotypic fertility results after artificial insemination in the three main French dairy cattle breeds. Renc Rech Rum, 12: 137-140.

3. Barnouin J, Chacornac JP (1992). A nutritional risk factor for early metritis in dairy farms in France. Prev Vet Med, 13: 27-37.

4. Bo GA, Hockley DK, Nasser LF, Mapletoft RJ (1994). Superovulatory response to a single subcutaneous injection of Folltropin- $\mathrm{V}$ in beef cattle. Theriogenology, 42: 963-975.

5. Bo GA, Pierson RA, Mapletoft RJ (1991). The effect of estradiol valerate on follicular dynamics and superovulatory response in cows with Syncro-Mate-B implants. Theriogenology, 36: 169-183.

6. Butler WR (2000). Nutritional interactions with reproductive performance in dairy cattle. Animal reproduction science, 60-61: 449-457.

7. Demoustier MM, Beckers JF, Van Der Zvalmen P, Closset J, Gillard JL, Ectors F (1988). Determination of plasma porcine follitropine level during superovulation treatment in cows. Theriogenology, 30: 379-386.

8. Dobson H, Tebble JE, Smith RF, Ward WR (2001). Is stress really all that important? Theriogenology, 55: 65-73.

9. Donaldson LE (1990). Superovulation in cattle. In: Proceedings 6th AETE meeting, Lyon; 7-8 septembre (pp. 136).

10. Drion PV, Beckers JF, Ectors FJ, Hanzen C, Houtain JY, Lonergan P (1996). Régulation de la croissance folliculaire et lutéale: 1 . Folliculogenèse et atrésie. Point Vét, 28: 881-891.

11. Eldsen RP, Nelson LD, Seidal GE (1978). Superovulating cows with follicle stimulating hormone and pregnant mare's serum gonadotropin. Thenogenology, 9: 17-26.

12. Ferrouk M, Gharbi I, Adel D, Lafri M, Touati K, Kaidi R, Guetarni D (2008). Production and transfer of embryos in Algerian "Cheurfa" bovine breed. Afr J Agric Res, 3: 320323.

13. Garcia Guerra A, Tribulo A, Yapura J, Singh J, Mapletoft RJ (2012). Lengthening the superstimulatory treatment protocol increases ovarian response and number of transferable embryos in beef cows. Theriogenology, 78: 353-360.

14. Ghozlane F, Yakhlef H, Allane M, Bouzida S (2006). Evaluation of the sustainability of dairy cattle farms in the Wilaya of Tizi-Ouzou (Algeria). New Medit, 5: 48-52.
15. Ghozlane MK, Atia A, Miles D, Khellef D (2010). Insémination artificielle en Algérie: Etude de quelques facteurs d'influence chez la vache laitière. Livestock Research for Rural Development, 22: 28.

16. Grizelj J, Vince S, Samardžija M, Gonzalez de Bulnes A, Dovenski T, Turmalaj L, Ževrnja B (2013). Use of ultrasonography to detect ovarian response in goats submitted to multiple ovulation and embryo transfer program. Vet Arhiv, 83: 125-134.

17. Hanzen C, Pieterse M, Scenczi O, Drost M (2000). Relative accuracy of the identification of ovarian structures in the cow by ultrasonography and palpation per rectum. Vet. J., 159: 161-170.

18. Hockley DK, Bo GA, Palasz AT, Del Campo MR, Mapletof RJ (1992). Superovulation with a single subcutaneous injection of Folltropin- $\mathrm{V}$ in the cow: effect of dose and site of injection. Theriogenology, 37: 224.

19. Kanitz W, Becker F, Schneider F, Kanitz E, Leiding C, Nohner HP, Pöhland R (2002). Superovulation in cattle: practical aspects of gonadotropin treatment and insemination. Reprod Nutr Dev, 42: 587-599.

20. Kelly P, Duffy P, Roche JF, Boland MP (1997). Superovulation in cattle: effect of FSH type and method of administration on follicular growth, ovulatory response and endocrine patterns. Ani. Reprod Sci, 46: 1-14.

21. Mapletoft RJ, Bo GA, Baruselli PS (2013). Control of ovarian function for assisted reproductive technologies in cattle. Anim Reprod, 6: 114-124.

22. Misra AK, Chaubal SA, Krishna Kishore G, Rajeshwaran S, Joshi BV, Jaiswal RS (1992). Superovulatory response to single subcutaneous injection of Folltropin in Holstein and Sahiwal cows. Theriogenology, 37: 260.

23. Monniaux D, Chupin D, Saumande J (1983). Superovulatory responses of cattle. Theriogenology, 19: 55-81.

24. Nibart M (1991). Embryo transfer and applied biotechnology: bisection and sexage. Rec Méd Vét, 167: 261-290.

25. Paragon BM (1991). Food quality and fertility in heifer and adult cow: importance of non-energy nutrients. Bull GTV, 91: 39-52.

26. Poncet J (2002). Etude des facteurs de risque de l'infertilité dans les élevages bovins laitiers de l'ile de la réunion/ influence de l'alimentation sur la reproduction. Thèse d'exercice. Ecole Nationale Vétérinaire de Toulouse, France.

27. Purwantara B, Callesen H, Greve T (1994). Characteristics of ovulations in superovulated cattle. Ani Reprod Sci, 37: 1-5.

28. Putney DJ, Drost M, Thatcher WW (1988). Embryonic development in superovulated dairy cattle exposed to elevated ambient temperatures between days 1 to 7 post insemination. Theriogenology, 30: 195-209. 
29. Rutledge JJ (2001). Use of embryo transfer and IVF to bypass effects of heat stress. Theriogenology, 55: 105-111.

30. Schröder UJ, Staufenbiel R (2006). Invited Review: Methods to determine body fat reserves in the dairy cow with special regard to ultrasonographic measurement of backfat thickness. J Dairy Sci, 89: 1-14.
31. Schutz MM, Pajor EA (2001). Genetic control of dairy cattle behavior. J Dairy Sci, 84 (E. Suppl.): E31-E38.

32. Tribulo A, Rogan D, Tribulo H, Mapletoft RJ, Bo GA (2012). Superovulation of beef cattle with a split-single intramuscular administration of folltropin- $V$ in tow concentrations of hyaluronan. Theriogenology, 77: 16791685. 